\title{
Extractive Separation of Scandium from Rare Earth Elements
}

\author{
Elena Zlobina *, Akmaral Ismailova, and Khajdar Tassibekov \\ Al-Farabi Kazakhstan National University, Almaty, Kazakhstan
}

\begin{abstract}
The extractive separation of scandium and rare earth metals (REM) was studied. The extractants used are trialkylbenzylammonium di-2-ethylhexylphosphate (TABAC-D2EHPA, binary extractant) and trioctylphosphine oxide (TOPO). The effect of concentration and nature of mineral acids on the scandium recovery was studied. Changing the $\mathrm{HNO}_{3}$ concentration in the range of $0.01-$ $2.0 \mathrm{~mol} / \mathrm{L}$ does not affect the extraction of metals by binary extractant, extraction corresponds to the following row: $\mathrm{La}, \mathrm{Eu}, \mathrm{Gd}<\mathrm{Tb}<\mathrm{Y}<\mathrm{Er}<\mathrm{Yb}<\mathrm{Sc}$, Th, that allows to separate scandium from rare earth metals by single extraction. Extraction of scandium by trioctylphosphineoxide from $\mathrm{HCl}$ solution proceeds quantitatively in the range of $0.5-7.0 \mathrm{~mol} / \mathrm{L}$, an increased $\mathrm{HNO}_{3}$ concentration leads to the decrease in scandium extraction. The conditions for the extractive separation of scandium and REM using TOPO solution were determined: scandium can be isolated selectively at the $\mathrm{HNO}_{3}$ concentration of $0.5 \mathrm{~mol} / \mathrm{L}$ REM are transferred into the organic phase at the $\mathrm{HNO}_{3}$ concentration of $5.0 \mathrm{~mol} / \mathrm{L}$. It was determined that the organic phase extracts the compounds of the following composition: $\left(\mathrm{ScA}_{3}+\mathrm{R}_{3} \mathrm{R}^{\prime} \mathrm{NCl}\right)\left(\mathrm{HA}-\mathrm{D}_{2} \mathrm{EHPA}, \mathrm{R}_{3} \mathrm{R}{ }^{\prime} \mathrm{NCl}-\mathrm{TABAC}\right)$ and $\left[\mathrm{Sc}\left(\mathrm{NO}_{3}\right)_{3} \cdot 3 \mathrm{TOPO}\right]$.
\end{abstract}

\section{Introduction}

The value of scandium and its compounds in the creation of new high-tech materials is continuously increasing. Scandium is used in the production of high-temperature ceramics, superhard materials, materials for a new generation of computers, laser crystals, high quality optical glass, alloys for the aerospace industry, and others $[1,2]$. The Republic of Kazakhstan has significant reserves of rare earth metals (REM). Industrially important content of scandium, yttrium, and rare-earth metals has been observed in uranium, titanium, zirconium, coal, phosphorus, aluminium deposits [3].

A variety of scandium-containing raw materials along with low target component, the complexity of scandium separation from the accompanying elements, especially close to REM in properties, does not allow the use of a universal method to extract it. After the acid or alkaline methods of the materials preparation in the course of the process chain there is a gradual concentration of scandium and rare-earth metals, which are mainly due to the use of extraction and precipitation processes. The process results in the concentrate, which is then separated into individual fractions or individual substances [4]. For scandium there is no selective extracting agent, which allows separating it along a large group of rare earth metals. There is only the way to create conditions under which scandium can be recovered with one or more cations.

The same neutral and cation-exchange reagents are used as industrial extractants for scandium and rare earth elements [5]. The degree of scandium extraction by di-(2-ethylhexyl)phosphoric acid (D2EHPA) is more than $90 \%$ of the solution with $\mathrm{HCl}$ concentration of $1 \mathrm{~mol} / \mathrm{L}$, but most of yttrium and the lanthanides remain in the raffinate [6]. The main disadvantage of D2EHPA is non-selectivity: $\mathrm{V}, \mathrm{Fe}, \mathrm{Zn}, \mathrm{Cu}, \mathrm{Co}, \mathrm{Ni}, \mathrm{Mn}$, $\mathrm{Mg}, \mathrm{Ca}$, together with scandium are transferred into the organic phase, moreover, solutions with high acid content must be used for back-extraction. Commercial extractants are used for separation of scandium from REE in the industry: $\operatorname{di}(2,4,4-$ trimethylpentyl)phosphinic acid (Cyanex272 bis(2,4,4trimethylpentyl)phosphinic acid) and Cyanex302 (bis(2,4,4-trimethylpentyl) monothiophosphinic acid), which is monothioanalogue of Cyanex272 [7].

Monocarboxylic acids also possess low selectivity; they are used for group concentration operations. Increase the extraction selectivity can be due to the use of mixtures of reagents, careful selection of extraction conditions $(\mathrm{pH}$, temperature, salting-out agents, thinners), as well as carrying out multi-stage processes. Authors of [8] used the solution of naphthenic acids and iso-octanol in kerosene as an extractant for separating scandium from REM. Twice extraction cycle allowed to achieve the separation factors for scandium from REE above $10^{4}$. During the first cycle, which includes 10 stages, scandium was concentrated from $0.02-0.04 \%$ to $15-20 \%$ of $\mathrm{Sc}_{2} \mathrm{O}_{3}$. In the second cycle, which includes 3 stages of extraction and back-extraction, the resulting scandium concentrate was purified to $99.99-99.999 \%$.

The results of extractive separation of REM, yttrium and scandium using alkylphosphine oxides of different composition from Cyanex 921, Cyanex 923, and Cyanex 925 trademarks as extractants from

\footnotetext{
*Corresponding author: zeva65@,mail.ru
} 
solutions of nitric, hydrochloric, sulfuric and phosphoric acids are given in [9-11]. It was shown that REM can be divided into four groups. The compositions of extracted complexes were determined, extraction mechanism was proposed, and extraction constants were calculated. It was shown that REM extraction efficiency increases in the following order: Cyanex $921>$ Cyanex $923>>$ Cyanex 925.

The use of binary extractants (BE), which are ion pairs formed by an organic base and an organic acid, is a promising direction in the extraction technology of some metals. The main advantages of binary extractants are: possibility of the prediction of $\mathrm{BE}$ properties based on the data on initial extraction systems; simplicity of obtaining the ion pair and availability of the extractants; increase in the distribution and separation coefficients; simplification of the back-extraction; high rates of extraction and back-extraction [12]. Dependences of binary extraction of REM were investigated by the authors of [13]. It is shown that the extractant selectivity for the cation depends on the nature of the organic acid, containing in the extractant. Adjacent pairs of lanthanides can be separated

with a separation factor of 2.5. It should be noted that some authors [14] called alkylammonium salts of various organic acids as ionic liquids or functionalized ionic liquids.

The problem of separation of scandium and rare earth metals is still not solved. The same extraction reagents are used for the extraction and separation of these metals. Since the new industrial reagents are not often created, the main objectives of a qualitative change in the technological schemes for REM and scandium are more complete study of existing reagents, selection of separation conditions, use of mixtures of extractants and their compounds, study of the complexforming properties of reagents.

The goal of this work was to study the extraction patterns and possible separation of scandium and rare earth metals by binary extractant trialkylbenzylammonium di-2-ethylhexylphosphate and solution of trioctylphosphine oxide in kerosene.

\section{Experimental part}

\subsection{Reagents, equipment, methods of analysis}

Standard solutions of scandium, yttrium and rare earth metals prepared according to standard procedures by dissolving the metal oxides in the appropriate acids were used. Working solutions of metals were prepared by diluting standard solutions to the desired concentration.

Solutions obtained after the microwave decomposition of mineral raw materials containing scandium, yttrium and rare earth elements were also used.

The content of all metals in the aqueous phase before and after extraction was determined by mass spectrometry with inductively coupled plasma (ICP-
MS) using Agilent 7500a mass spectrometer. Operating parameters of the spectrometer are as follows: plasma gas flow rate - $15 \mathrm{~L} / \mathrm{min}$; carrier gas flow rate -0.8 $1.3 \mathrm{~L} / \mathrm{min}$; plasma temperature - $8000{ }^{\circ} \mathrm{C}$; signal integration time - 0.1 seconds; high-frequency signal power - 1200-1400 W. Calibration solutions for mass spectrometric analysis were prepared from MultiElement Calibration Standard-1 and Multi-Element Calibration Standard-2A standard solutions (Agilent Technologies). Nitric acid of high purity grade was used for preparation of the solutions; all solutions were prepared using twice-distilled water.

The $\mathrm{pH}$ was adjusted using sodium hydroxide, ammonia and hydrochloric acid solutions. Hydrogen ions concentration was monitored using I-160MI ionomer with ES-10603 glass electrode standardized by buffer solutions.

\subsection{Extractants, extraction technique}

Trioctylphosphine oxide $\left(\mathrm{C}_{8} \mathrm{H}_{17}\right)_{3} \mathrm{PO}$ (TOPO) and binary extractants were used as extraction reagents.

For preparation of binary extractants D2EHPA, di2-ethylhexyldithiophosphoric acid (D2EHDTPA), trioctylamine (TOA) and trialkylbenzylammonium chloride (TABAC) were used. Ion pairs obtained by contacting solutions of TABAC $\left(\mathrm{R}_{3} \mathrm{R}^{\prime} \mathrm{NCl}\right)$ with organic acids in heptane in $1: 1$ ratio with $2 \mathrm{~mol} / \mathrm{L}$ sodium hydroxide solution for 10 minutes. Contacting the organic phase and the alkaline solution was repeated three times, refreshing $\mathrm{NaOH}$ solution. After separation, the organic phase was washed with water to neutral $\mathrm{pH}$. Ion pairs TOA - D2EHPA obtained by contacting solutions of TOA $\left(\left(\mathrm{C}_{8} \mathrm{P}_{17}\right)_{3} \mathrm{~N}\right)$ with D2EHPA in heptane in $1: 1$ ratio for 10 minutes. Composition of the BE obtained is given in Table 1 . Kerosene and heptane were used as diluents.

The technique for metals extraction was as follows: the exact volume of metal solution was placed into a separatory funnel having a certain value of the acid concentration, an aliquot of an extractant was added, and the extraction was carried out by shaking the separatory funnel by hand for 5 minutes. Preliminary experiments showed that this time is enough to establish equilibrium in the system. All experiments were performed at $25 \pm 1{ }^{\circ} \mathrm{C}$. Further, the phases were separated; the metal content in the water phase was controlled using ICP-MS method. The metal content in the organic phase was determined by the difference between its content in the solution before and after extraction.

Distribution coefficients (D) were calculated according to the equation:

$$
D=\frac{C_{o}}{C_{a}},
$$

where $\mathrm{C}_{\mathrm{o}}$ and $\mathrm{C}_{\mathrm{a}}$ are metal concentrations in the organic and aqueous phases.

Recovery rate $(\mathrm{R}, \%)$ was calculated based on the relationship: 


$$
R=\frac{D}{D+V_{a} / V_{o}} \cdot 100 \%,
$$

where $\mathrm{V}_{\mathrm{a}}$ and $\mathrm{V}_{\mathrm{o}}$ are the volumes of the aqueous and organic phases.

Metal separation efficiency was evaluated by calculating the value of the enrichment degree (r), showing each metal fraction in the total amount of metals in the solution. The enrichment degree was calculated using the formula:

$$
r=\frac{C_{M e}}{C_{\text {total }}} \cdot 100 \%,
$$

where $\mathrm{C}_{\mathrm{Me}}$ is metal concentration, $\mathrm{mg} / \mathrm{dm}^{3}, \mathrm{C}_{\text {total }}$ is the sum of the concentrations of all metals in the solution, $\mathrm{mg} / \mathrm{dm}^{3}$.

Table 1. Composition of binary extractants.

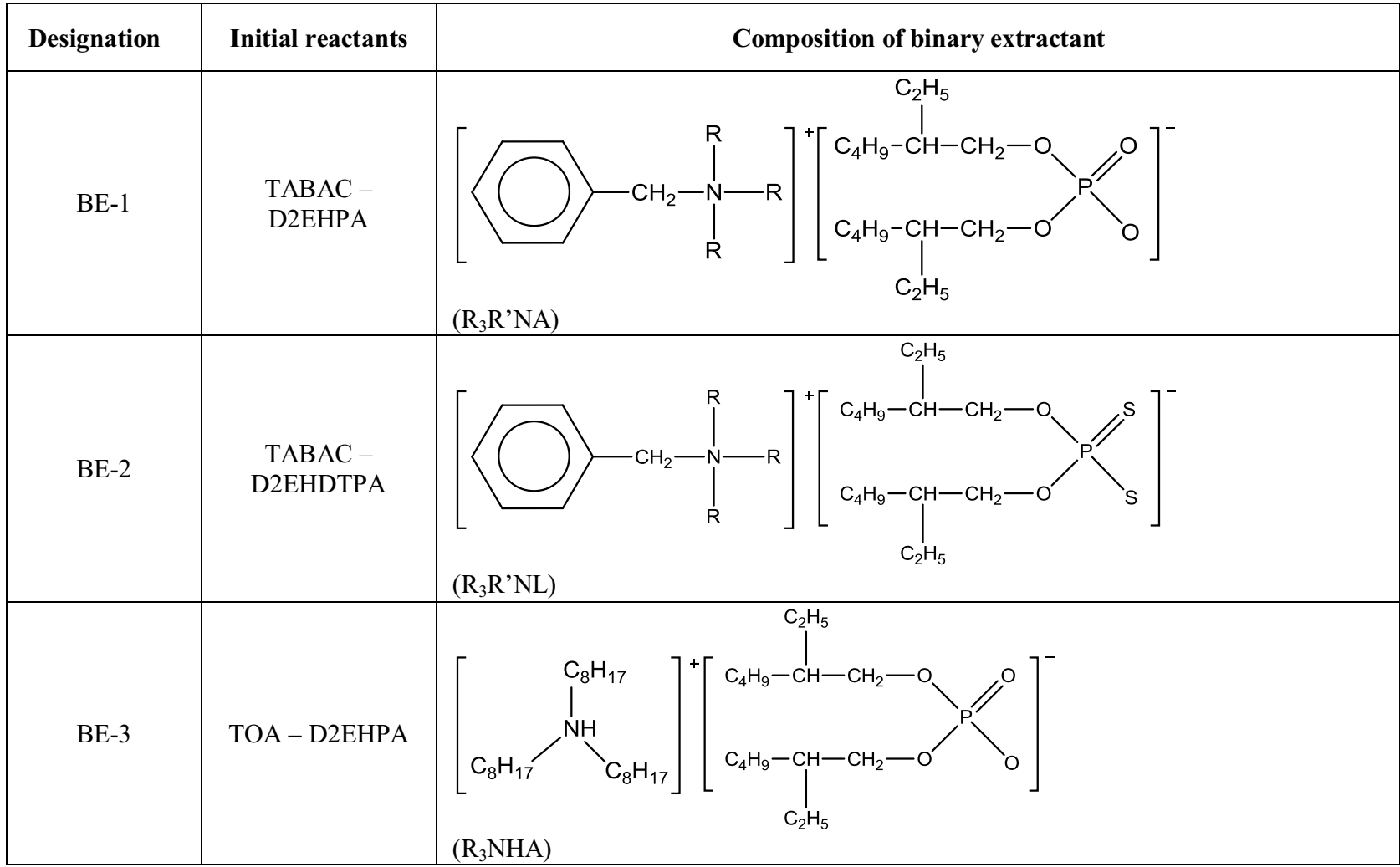

\section{Results and discussion}

\subsection{Extraction of scandium using binary extractants of different composition}

Extraction behavior of binary extractants can be predicted when considering the patterns of the metals extraction by reagents used for the preparation of $\mathrm{BE}$. In the nitrate solutions scandium is in the form of a hydrated $\left[\mathrm{Sc}\left(\mathrm{H}_{2} \mathrm{O}\right)_{6}\right]^{3+}$ cation, therefore it can be extracted effectively by cation exchange extractants. $\mathrm{BE}$ properties are related to the properties of the initial systems, so cation exchange extractant, which is part of the binary extractant affects the degree of extraction of scandium. Previously, it was found that D2EHPA effectively (over $95 \%$ ) extracts scandium in a wide range of the aqueous phase acidity; the degree of extraction using D2EHDTPA does not exceed $80-95 \%$ [15].

Extraction of scandium using BE of different composition was studied depending on the concentration of $\mathrm{HNO}_{3}$, which was varied in the range of $0.01-3.0 \mathrm{~mol} / \mathrm{L}$ (Fig. 1).

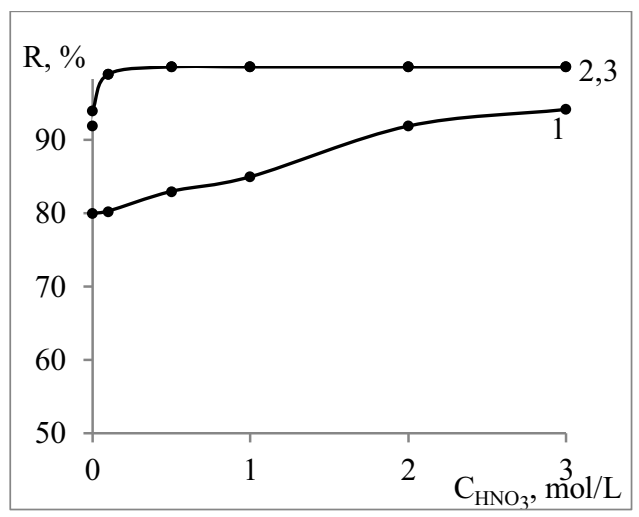

Fig. 1. Extraction of scandium using $B E$ of different composition: 1 - TABAC-D2EHDTPA; 2 - TOAD2EHPA; 3 - TABAC-D2EHPA; $\mathrm{C}_{\mathrm{Sc}}=1.0 \cdot 10^{-4} \mathrm{~mol} / \mathrm{L} ; \mathrm{C}_{\mathrm{ex}}$ $=0.1 \mathrm{~mol} / \mathrm{L}$

From these data, it follows that BE containing TABAC-D2EHPA and TOA-D2EHPA quantitatively extract scandium from solution with the nitric acid concentration of $0.1-3.0 \mathrm{~mol} / \mathrm{L}$. Extracting scandium using BE containing TABAC-D2EHDTPA has been increased from 80 to $95 \%$ at $\mathrm{HNO}_{3}$ 
concentration increase from 0.01 to $3.0 \mathrm{~mol} / \mathrm{L}$. Binary extractant of TABAC-D2EHPA composition was selected for further research.

\subsection{Study of the effect of mineral acid concentration}

The main method of decomposition of scandiumcontaining natural and man-made samples is the dissolution in mineral acids, therefore, the effect of $\mathrm{HCl}$ and $\mathrm{HNO}_{3}$ concentrations on the extraction of scandium by binary extractants and TOPO was studied. The results are shown in Figures 2 and 3.

The degree of cation extraction in binary extraction of metal salts is affected by the nature of the anion. Obtained data shows that the extraction of scandium by BE of TABAC-D2EHPA composition from nitric acid solutions proceeds more effectively than from solutions of hydrochloric acid in the concentration range of $0.1-3.0 \mathrm{~mol} / \mathrm{L}$.

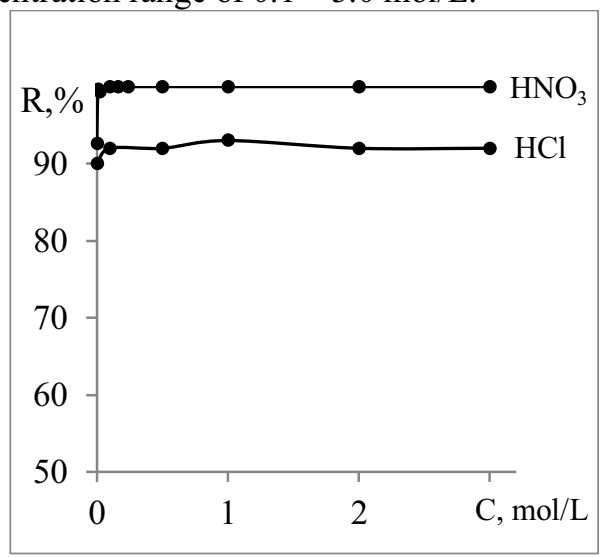

Fig. 2. Extraction of scandium by $0.1 \mathrm{~mol} / \mathrm{L}$ solution of TABAC-D2EHPA in heptane depending on the concentration of mineral acid: $\mathrm{C}_{\mathrm{Sc}}=1.0 \cdot 10^{-4} \mathrm{~mol} / \mathrm{L} ; \mathrm{O}: \mathrm{W}=$ $1: 10 ; \tau=5 \mathrm{~min} ; \mathrm{T}=25^{\circ} \mathrm{C}$.

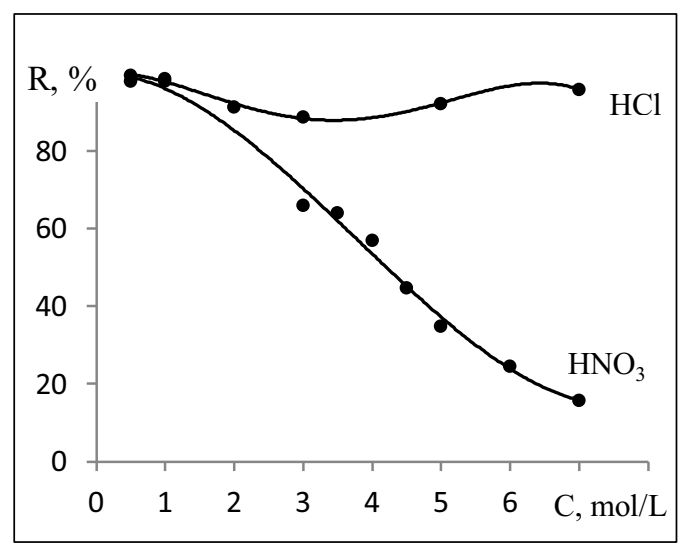

Fig. 3. Extraction of scandium by $0.01 \mathrm{M}$ solution of TOPO in kerosene depending on the concentration of mineral acid: $\mathrm{C}_{\mathrm{Sc}}=1.0 \cdot 10^{-4} \mathrm{~mol} / \mathrm{L} ; \mathrm{O}: \mathrm{W}=1: 10 ; \tau=5 \mathrm{~min}$; $\mathrm{T}=25^{\circ} \mathrm{C}$.

The findings are consistent with the extraction raw for the initial anion exchange systems with $\mathrm{QAB}$ salts. Binary extraction of scandium is not dependent on the solution $\mathrm{pH}$, unlike cation exchange systems, since the increase in the concentration of hydrochloric acid remains the extraction degree of scandium unchanged.

Extraction of scandium using TOPO-kerosene solution from hydrochloric acid solutions proceeds more efficiently than from nitric acid solutions in the concentrations range of $2.0-7.0 \mathrm{~mol} / \mathrm{L}$. Increasing $\mathrm{HNO}_{3}$ concentration reduces the extraction of scandium.

\subsection{Study of the effect of scandium concentration in the aqueous phase}

Metal ion species in the aqueous and organic phases are different, so the metal distribution ratios depend on the initial concentration of the element in the aqueous phase. Scandium extraction by TABACD2EHPA-heptane and TOPO-kerosene solutions was performed varying the concentration of metal in the aqueous phase. Figures 4 and 5 show the isotherms of scandium extraction.

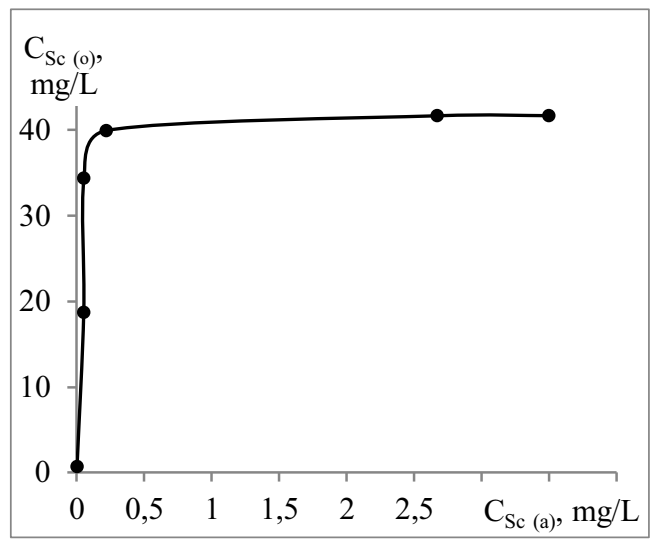

Fig. 4. The isotherms of scandium extraction by binary extractant TABAC-D2EHPA-heptane: $\mathrm{C}_{\mathrm{BE}}=0.01 \mathrm{~mol} / \mathrm{L}$; $\mathrm{C}_{\mathrm{HNO}_{3}}=1.0 \mathrm{~mol} / \mathrm{L} ; \mathrm{O}: \mathrm{W}=1: 1 ; \tau=10 \mathrm{~min}$.

The capacity of $0.01 \mathrm{M}$ TABAC-D2EHPA for scandium is $40 \mathrm{mg} / \mathrm{L}$. Distribution of scandium in binary systems (excluding the possible interactions in the organic phase) can be described by the following scheme:

$$
\begin{aligned}
& 3 \mathrm{R}_{3} \mathrm{R}^{\prime} \mathrm{NA}_{(\mathrm{o})}+\mathrm{Sc}^{3+}{ }_{(\mathrm{a})}+3 \mathrm{NO}_{3}^{-}{ }_{(\mathrm{a})} \rightarrow \\
& \rightarrow \mathrm{ScA}_{3(\mathrm{o})}+3\left[\mathrm{R}_{3} \mathrm{R}^{\prime} \mathrm{N}^{-} \mathrm{NO}_{3(\mathrm{o})}\right.
\end{aligned}
$$

Capacity of $0.001 \mathrm{M}$ solution of TOPO in kerosene for scandium is $\sim 7.7 \mathrm{mg} / \mathrm{L}$. As can be seen from the figure, when the scandium concentration in the aqueous phase is more than $12 \mathrm{mg} / \mathrm{L}$ isotherm line becomes parallel to the abscissa, indicating the scandium saturation of extractant.

The process of scandium extraction by TOPOkerosene solution can be represented by the scheme:

$\mathrm{Sc}^{3+}{ }_{\mathrm{a}}+3 \mathrm{NO}_{3 \mathrm{a}^{-}}+3 \mathrm{TOPO}_{\mathrm{o}}=\left[\mathrm{Sc}\left(\mathrm{NO}_{3}\right)_{3} \cdot 3 \mathrm{TOPO}\right]_{\mathrm{o}}$

Equation for scandium extraction constant by TOPO-kerosene solution has the following form:

$$
\begin{array}{r}
K_{e x}=\frac{\left[\mathrm{Sc}\left(\mathrm{NO}_{3}\right)_{3} * 3 \mathrm{TOPO}\right]_{\mathrm{o}}}{\left[\mathrm{Sc}^{3+}\right]_{a}\left[\mathrm{NO}_{3}^{-}\right]_{a}^{3}[\mathrm{TOPO}]_{0}^{3}} \\
\lg K_{e x}=5,84
\end{array}
$$




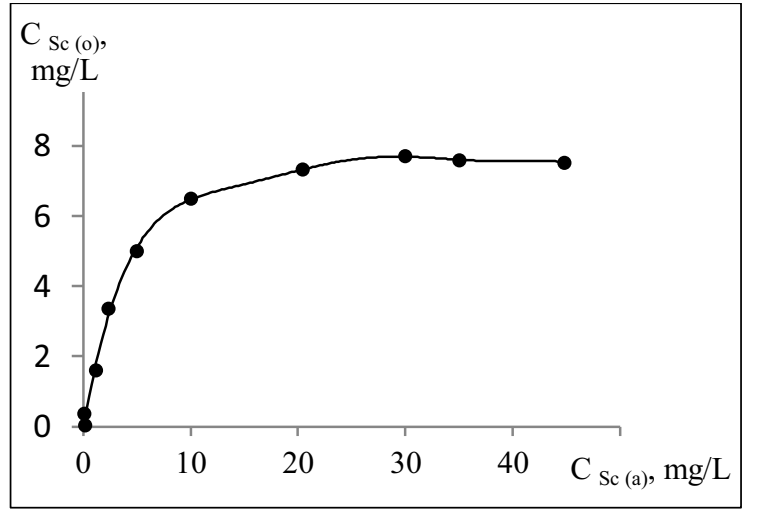

Fig. 5. The isotherms of scandium extraction by TOPOkerosene: $\mathrm{C}_{\mathrm{TOPO}}=0.001 \mathrm{~mol} / \mathrm{L} ; \mathrm{C}_{\mathrm{HNO}_{3}}=0.5 \mathrm{~mol} / \mathrm{L}$; $\mathrm{O}: \mathrm{W}=1: 1$.

\subsection{Study of the separation of scandium and rare-earth metals}

Extractive separation of scandium and rare-earth elements was carried out using $0.1 \mathrm{~mol} / \mathrm{L}$ solution of
TABAC-D2EHPA binary extractant in heptane, the concentration of metals was $400 \mu \mathrm{g} / \mathrm{L}$.

The concentration of nitric acid in the aqueous phase was varied in the range of $0.01-2.0 \mathrm{~mol} / \mathrm{L}$. Dependence of the extraction degree from the nitric acid concentration is shown in Figure 6.

Varying the concentration of nitric acid in the range of $0.01-2.0 \mathrm{~mol} / \mathrm{L}$ has almost no effect on the extraction of scandium, thorium, yttrium, rare-earth metals at the joint presence. Scandium and thorium was transferred quantitatively into the organic phase $(>95 \%)$.

The degree of $\mathrm{Yb}$ extraction does not exceed 58 $\%$, Er, Y - 30 \%, Tb, La, Gd, Eu - 18 \%. Extraction corresponds to the following row: $\mathrm{La}, \mathrm{Eu}, \mathrm{Gd}<\mathrm{Tb}<$ $\mathrm{Y}<\mathrm{Er}<\mathrm{Yb}<\mathrm{Sc}$, Th, which is consistent with the cation exchange row of D2EHPA, but in the case of binary extraction recovery rates are constant with changes in nitric acid concentration. This allows to obtain concentrates of scandium, yttrium and rareearth metals with the ratio specified in Table 2 at the nitric acid concentration of $0.01-2.0 \mathrm{~mol} / \mathrm{L}$.

Table 2. Degree of enrichment by rare-earth metals during the extraction by binary extractant of TABAC-D2EHPA composition.

\begin{tabular}{|c|c|c|c|c|c|c|c|c|c|}
\hline & \multicolumn{9}{|c|}{ Degree of enrichment, \% } \\
\cline { 2 - 14 } & $\mathrm{Sc}$ & $\mathrm{Y}$ & $\mathrm{La}$ & $\mathrm{Eu}$ & $\mathrm{Gd}$ & $\mathrm{Tb}$ & $\mathrm{Er}$ & $\mathrm{Yb}$ & $\mathrm{Th}$ \\
\hline Without acid & 11.0 & 11.3 & 11.3 & 11.2 & 11.2 & 11.3 & 11.5 & 11.1 & 10.2 \\
\hline In $\mathrm{HNO}_{3}$ solution & 32.3 & 7.4 & 1.0 & 1.2 & 1.4 & 2.2 & 9.5 & 15.6 & 29.3 \\
\hline
\end{tabular}

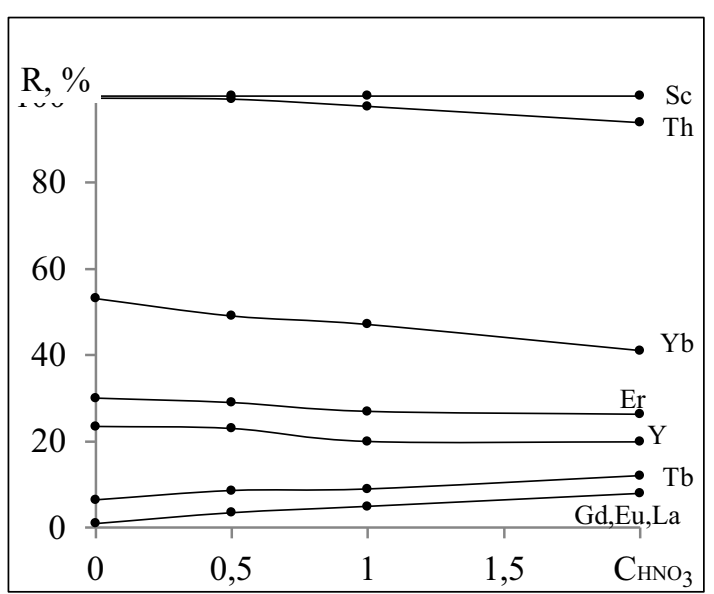

Fig. 6. Extraction of metals by TABAC-D2EHPA at the joint presence: $\mathrm{C}_{\mathrm{ex}}=0.1 \mathrm{~mol} / \mathrm{L} ; \mathrm{C}_{\mathrm{Me}}=400 \mu \mathrm{g} / \mathrm{L}$.

The recovery of scandium by TOPO-kerosene solution at $\mathrm{C}\left(\mathrm{HNO}_{3}\right)=7.0 \mathrm{~mol} / \mathrm{L}$ does not exceed $15 \%$, which suggests that at high $\mathrm{HNO}_{3}$ concentrations scandium and related metals can be separated. Therefore, extractive separation of metals was studied using model solution by TOPO-kerosene extractant varying nitric acid concentrations in the range of $0.5-5.0 \mathrm{~mol} / \mathrm{L}$.

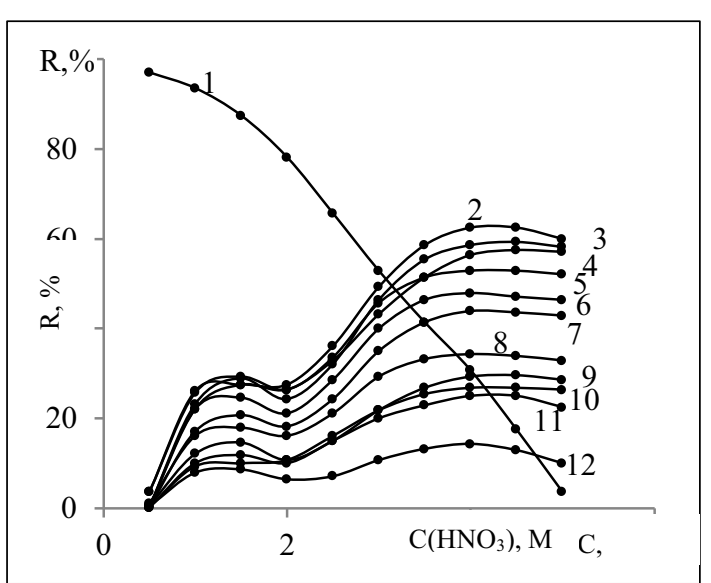

Fig. 7. Extraction of scandium and REM by $0.01 \mathrm{M}$ solution of TOPO-kerosene depending on the concentration of $\mathrm{HNO}_{3}: 1$ - Sc; 2 - Yb; 3 - Er; 4 - Dy; 5 - Sm; 6 - Gd; 7 - Nd; 8 - Eu; 9 - Lu; 10 - Tm; $11-\mathrm{Ho}, \mathrm{Tb}, \mathrm{Pr}, \mathrm{Ce}, \mathrm{La} ; 12$ $-\mathrm{Y} ; \mathrm{C}_{\mathrm{Me}}=40 \mu \mathrm{g} / \mathrm{L}, \mathrm{C}_{\mathrm{Sc}}=450 \mu \mathrm{g} / \mathrm{L}$.

Besides scandium model solution contained the following rare-earth metals: $\mathrm{Ce}, \mathrm{Pr}, \mathrm{Nd}, \mathrm{Sm}, \mathrm{Eu}, \mathrm{Gd}$, Tb, Dy, Ho, Er, Tm, Yb, Lu, Th, Y and La, moreover REM concentration was $40 \mu \mathrm{g} / \mathrm{L}$, concentration of Sc was $450 \mu \mathrm{g} / \mathrm{L}$. The results are shown in Figure 7.

As can be seen from the data, the degree of scandium extraction is reduced with increasing concentration of nitric acid, and not exceeding $5 \%$ at $\mathrm{C}\left(\mathrm{HNO}_{3}\right)=5.0 \mathrm{~mol} / \mathrm{L}$, at the same time the extraction of rare-earth metals increases. Thus, when nitric acid 
concentration is $0.5 \mathrm{~mol} / \mathrm{L}$, it is possible to separate scandium from rare earth impurities using TOPOkerosene solution; rare earth impurities remain in the aqueous phase under given conditions. However, if the nitric acid concentration is $5.0 \mathrm{~mol} / \mathrm{L}$ rare-earth metals impurities are transferred into the organic phase unlike scandium. REE can be extracted quantitatively under these conditions by performing multiple extractions by TOPO-kerosene solution. In this case, it is possible to manage the production stage without back-extraction of scandium from the organic to the aqueous phase. This will reduce the number of operations and the amount of reagents used.

\section{Conclusion}

The extraction patterns of scandium by binary extractants of different composition have been studied: trialkylbenzylammonium di-2ethylhexyldithiophosphate, trialkylbenzylammonium di-2-ethylhexylphosphate, trioctylammonium di-2ethylhexylphosphate and solution of trioctylphosphine oxide in kerosene.

The effect of concentration and nature of mineral acids on the extraction of scandium have been studied. Binary extractants based on D2EHPA allow extracting scandium from the solution most effectively, the presence of TABAC branched cation makes the binary extractant selective. The extraction of scandium by binary D2EHPA-TABAC extractant depends on the nature of the mineral acid in aqueous solution. From the solutions of nitric acid with concentrations of $0.1-3.0 \mathrm{~mol} / \mathrm{L}$ scandium is extracted quantitatively, the recovery from solution of hydrochloric acid does not exceed $90 \%$. The nature of mineral acid affects the scandium extraction by TOPO-kerosene solution. In the wide range of $\mathrm{HCl}$ concentration, $0.5-7 \mathrm{~mol} / \mathrm{L}$, scandium is extracted quantitatively into the organic phase. With increase in $\mathrm{HNO}_{3}$ concentration scandium extraction is reduced not exceeding $15 \%$ at $\mathrm{C}\left(\mathrm{HNO}_{3}\right)=7 \mathrm{~mol} / \mathrm{L}$.

Based on the extraction isotherms the capacities of the extractants by scandium were determined, which are $40 \mathrm{mg} / \mathrm{L}$ for $0.01 \mathrm{~mol} / \mathrm{L}$ TABAC-D2EHPA and $7.7 \mathrm{mg} / \mathrm{L}$ for $0.001 \mathrm{~mol} / \mathrm{L}$ TOPO solution. It was determined that the organic phase extracts the compounds of the following composition: $\left(\mathrm{ScA}_{3}+\right.$ $\left.\mathrm{R}_{3} \mathrm{R}^{\prime} \mathrm{NCl}\right)$ and $\left[\mathrm{Sc}\left(\mathrm{NO}_{3}\right)_{3} \cdot 3 \mathrm{TOPO}\right.$.

Study of scandium and REM separation showed that during the binary extraction scandium and thorium are transferred into the organic phase quantitatively (over $95 \%$ ) and the extraction degree of $\mathrm{Yb}$ does not exceed $58 \%, \mathrm{Er}, \mathrm{Y}-30 \%$, Tb, La, $\mathrm{Gd}, \mathrm{Eu}-18 \%$. Extraction corresponds to the following row: $\mathrm{La}, \mathrm{Eu}, \mathrm{Gd}<\mathrm{Tb}<\mathrm{Y}<\mathrm{Er}<\mathrm{Yb}<\mathrm{Sc}$, $\mathrm{Th}$, which is consistent with the cation exchange row of D2EHPA, but in the case of binary extraction recovery rates are constant with changes in nitric acid concentration. The conditions for the extractive separation of scandium and REM using TOPO solution were determined. Scandium can be isolated selectively into the organic phase at the $\mathrm{HNO}_{3}$ concentration of $0.5 \mathrm{~mol} / \mathrm{L}, \mathrm{REM}$ are transferred into the organic phase at the $\mathrm{HNO}_{3}$ concentration of 5.0 $\mathrm{mol} / \mathrm{L}$.

\section{References}

1. A.V. Naymov, Proceedings of Higher Schools Nonferrous Metallurgy (in Russian - Izvestiya Vuzov. Tsvetnaya Metallurgiya) 1, 22 (2008)

2. S. Jacenko, V. Diev, B. Ovsjanikov, Eurasian Metals (in Russian - Metally Evrazii) 4, 60 (2004)

3. N.S. Bekturganov, M.A. Najmanbaev, T.Ju. Surkova, Non-ferrous Metals (in Russian Tsvetnye Metally) 4, 48 (2010)

4. W. Weiwei, P. Yoko, Y.C. Chu, Hydrometallurgy 108, 100 (2011)

5. X. Feng, T.A. Zhang, D. Dreisinger, F. Doyle, Miner. Eng. 56, 10 (2014)

6. M. Ochsenkuhn-Petropulu, Th. Lyberopulu, G. Parissakis, Anal. Chim. Acta. 315, 231 (1995)

7. M. Karve, Bh. Vaidya, Sep. Sci. Technol. 43, $1111(2008)$

8. C. Liao, G. Xu, J. Jia, Y. Zhang, S. Wu, C. Yan, J. Chin. Rare Earth Soc. 19, 289 (2001)

9. B. Gupta, A. Malik, A. Deep, Solvent Extr. Ion Exch. 21, 239 (2003)

10. D. Li, C. Wang, Hydrometallurgy 48, 301 (1998)

11. Y.A. El-Nadi, N.E. El-Hefny, J. A. Daoud, Solvent Extr. Ion Exch. 25, 225 (2007)

12. A.I. Hol'kin, Chemical Technology (in Russian Khimicheskaya Tehnologiya) 5, 3 (2000)

13. V.V. Belova, A.A. Voshkin, A.I. Kholkin, A.K. Payrtman, Hydrometallurgy 97, 198 (2009)

14. X. Sun, H. Luo, S. Dai, Talanta, 90, 132 (2012)

15. E.V. Zlobina, L.O. Pak, Chemical Bulletin of Kazakh National University (in Russian - Vestnik KazNU. Suriya Himicheskaya) 4, 168 (2013) 